\title{
Capsaicin Activates a Nonselective Cation Channel in Cultured Neonatal Rat Dorsal Root Ganglion Neurons
}

\author{
Uhtaek Oh, ${ }^{1}$ Sun Wook Hwang, ${ }^{1}$ and Donghee Kim ${ }^{2}$ \\ ${ }^{1}$ Section of Physiology, College of Pharmacy, Seoul National University, Seoul 151-742, Korea, and 'Department of \\ Physiology and Biophysics, Finch University of Health Sciences/Chicago Medical School, North Chicago, Illinois 60064
}

Capsaicin (CAP), a neurotoxin, has been reported to activate a nonselective cation current in dorsal root ganglion (DRG) neurons. In this paper, we identify and describe the properties of CAP-activated single channels in cultured neonatal rat DRG neurons. We first identified CAP-sensitive whole-cell currents that reversed near $0 \mathrm{mV}$ in physiological solution. In solution containing $140 \mathrm{~mm} \mathrm{Na}{ }^{+}$, extracellular application of CAP to outside-out patches caused activation of an ion channel in a concentration-dependent manner $\left(\mathrm{EC}_{50}=1.1 \mu \mathrm{M}\right)$. The channel was blocked by the CAP antagonist capsazepine $(10 \mu \mathrm{M})$. The channel was also activated by $2-10 \mathrm{~nm}$ resiniferatoxin, a potent analog of CAP. In symmetrical $140 \mathrm{mM} \mathrm{Na}^{+}$, the single-channel slope conductances were $45.3 \pm 1.0$ and $80.0 \pm 4.2 \mathrm{pS}$ at -60 and $+60 \mathrm{mV}$, respectively, showing outward rectification $(n=$
9). The reversal potential did not shift significantly when $\mathrm{Na}^{+}$ was replaced by $\mathrm{K}^{+}, \mathrm{Cs}^{+}, \mathrm{Rb}^{+}$, or $\mathrm{Li}^{+}$, showing that the channel discriminated poorly among cations. The channel was also permeable to $\mathrm{Ca}^{2+}$. Although acid $(\mathrm{pH}<6.2)$ was suggested to be an endogenous activator of the CAP receptor, an acid solution $(\mathrm{pH} \mathrm{5.9-6.0)}$ failed to activate the channels in outside-out patches. This is the first clear demonstration of the presence of the CAP-activated ion channel in DRG neuron. Opening of these ligand-gated, cation-selective channels gives rise to the whole-cell CAP-activated current in DRG neurons and may underlie the neurotoxic effects of CAP.

Key words: capsaicin; nonselective cation channel; capsazepine; resiniferatoxin; DRG; pain
Capsaicin (CAP) is a pungent ingredient in hot peppers of the genus Capsicum and is eaten daily by many people worldwide. After application on the skin, CAP causes an immediate and intense burning pain as well as neurngenic hyperalgesia (Simnne et al., 1987, 1989, 1991). In addition, CAP causes desensitization to various noxious stimuli (Maggi et al., 1988, 1989; Dray et al., 1989), thus producing a long-lasting analgesia (Hayes et al., 1981) (for review, see Holtzer, 1991). CAP also causes a morphological change, leading to permanent damage in the sensory nerves (Jancsó et al., 1977; Nagy and Hunt, 1983; Nagy et al., 1983). The neurotoxic actions of CAP are restricted mainly to small-diameter sensory fibers (Szolcsanyi, 1987; LaMotte et al., 1988; Lang et al., 1990). These actions of CAP on small sensory nerve fibers provide a good experimental tool in neurobiological studies, and also draw clinical interest as potentially useful analgesics (for review, see Holtzer, 1991; Szallasi and Blumberg, 1993).

In dorsal root ganglion (DRG) neurons, high-affinity binding sites specific for CAP have been identified (Szallasi and Blumberg, 1990, 1991; Winter et al., 1993). Strict structural requirements for CAP action and the presence of the competitive antagonist capsazepine (CZP) have demonstrated further the presence of specific binding sites or receptors for CAP in DRG neurons (Szolcsanyi and Jancsó-Gabor, 1975, 1976; Dickenson and Dray, 1991; Bevan et al., 1992; Walpole et al., 1993). Earlier studies showed that depolarization of the sensory nerve by CAP was

Received Aug. 28, 1995; revised Dec. 2, 1995; accepted Dec. 12, 1995.

This work was supported by an RCNDD grant from the Korea Science and Engineering Foundation, and a Genetic Engineering Research Grant provided by the Ministry of Education of Korca.

Correspondence should be addressed to Uhtaek Oh, Section of Physiology, College of Pharmacy, Seoul National University, Kwanak, Shinlim San 56-1, Scoul $151-742$, Korea.

Copyright $(\mathcal{C} 1996$ Society for Neuroscience $0270-6474 / 96 / 161659-09 \$ 05.00 / 0$ associated with an increase in ion conductance (Marsh et al., 1987), suggesting that the CAP receptor may be coupled to ion channels. In cultured DRG neurons, CAP increased fluxes of various cations in a dose-dependent manner (Wood et al., 1988). More recently, CAP was shown to produce an inward current in cultured DRG and trigeminal ganglion neurons (Bevan et al., 1992; Liu and Simon, 1994). The inward current elicited by CAP was blocked by CZP, and the reversal potential of the CAPinduced current was near $0 \mathrm{mV}$ (Bevan et al., 1992; Liu and Simon, 1994). Thus, these studies suggest that a nonselective ion channel is gated by CAP binding to its receptor.

Although a few studies have characterized ionic fluxes and whole-cell currents evoked by CAP, single channels responsible for the macroscopic CAP-induced currents have not yet been identified clearly. In this paper, we identified both the whole-cell and single-channel currents activated by CAP and its potent analog, resiniferatoxin (RTX), in cell-attached and excised membrane patches of DRG neurons. Activation of the channel by CAP was antagonized by $\mathrm{CZP}$. Interestingly, acid $(\mathrm{pH}<6.2)$, which was considered as an endogenous activator of the CAP-sensitive current (Bevan and Yeats, 1991; Bevan and Geppetti, 1994; Liu and Simon, 1994), failed to activate the nonselective cation channel in our study.

\section{MATERIALS AND METHODS}

Cell culture. DRG neurons from all levels of thoracic and lumbar spinal cord of 1-d-old neonatal rats were dissected and collected in cold culture medium $\left(4^{\circ} \mathrm{C}\right)$. The culture medium was a mixture of DMEM and F-12 solution (Sigma, St Louis, MO) that contained $10 \%$ fetal bovine serum (Gibco, Grand Island, NY), $1 \mathrm{~mm}$ sodium pyruvate, $50-100 \mathrm{ng} / \mathrm{ml}$ nerve growth factor (Sigma), and $100 \mathrm{U} / \mathrm{ml}$ penicillin/streptomycin (Sigma). Ganglia were washed with a mixture of DMEM and F-12 solution and then incubated for $30 \mathrm{~min}$ in warm $\left(37^{\circ} \mathrm{C}\right)$ DMEM and F. 12 mixture containing $1 \mathrm{mg} / \mathrm{ml}$ collagenase (Worthington, Freehold, NJ). The gan- 


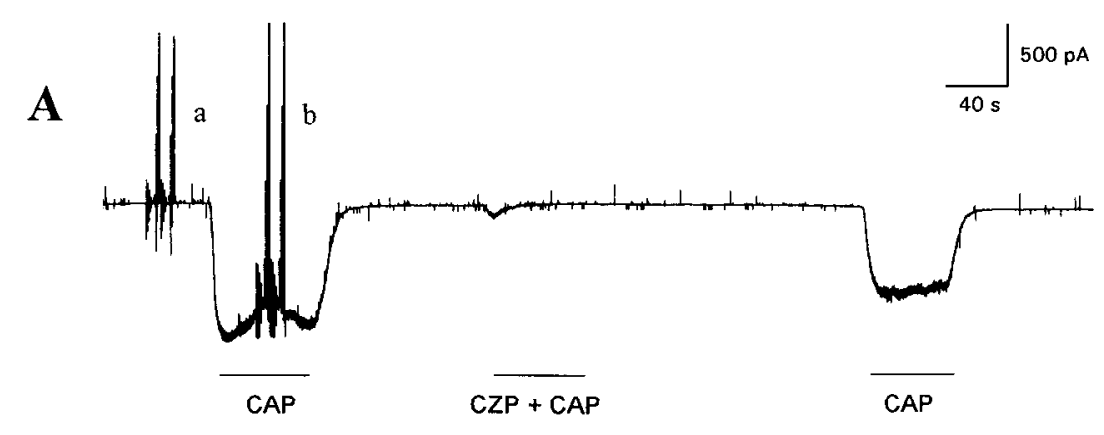

\section{B}

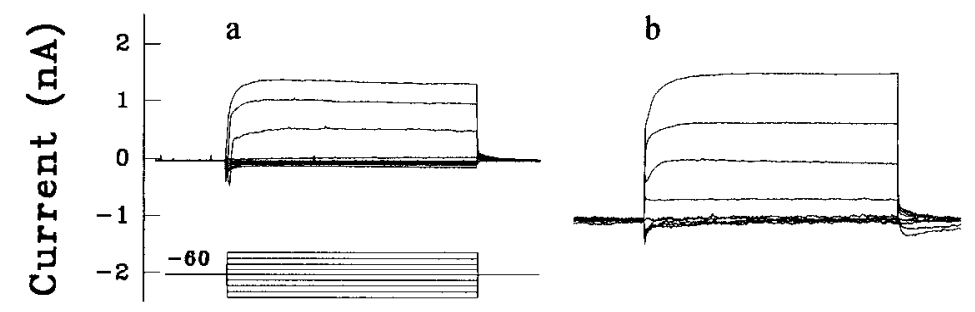

Figure 1. Whole-cell currents evoked by CAP. $A, A$ DRG neuron was perfused with $C A P(3 \mu \mathrm{M})$ for $\sim 1 \mathrm{~min}$ and washed out at a rate of $10 \mathrm{ml} / \mathrm{min}$. After the first CAP application, $C Z P+C A P(10$ and $3 \mu \mathrm{M}$, respectively) solution was perfused. Pipette solution contained (in $\mathrm{mM}$ ): $140 \mathrm{~K}^{+}$and 4 ATP. Control bath solution contained (in mu): $140 \mathrm{Na}^{+}, 140 \mathrm{Cl}^{-}, 5 \mathrm{~K}^{+}, 2 \mathrm{Mg}^{2+}, 1 \mathrm{Ca}^{2+}, 10$ HEPES, and 10 glucose. During perfusion, membrane potential was briefly changed to -140 to $+20 \mathrm{mV}(a, b)$ to observe changes in inward and outward currents. $B$, Whole-cell currents elicited by voltage steps ranging from -140 to $+20 \mathrm{mV}$ in $20 \mathrm{mV}$ steps. Square pulses of different potentials in $400 \mathrm{msec}$ duration (inset) were delivered to the whole cell in every second. The voltage steps were repeated twice, and the currents were averaged. $a$, Control currents; $b$, currents elicited during CAP perfusion. $C$, Steady-state current-voltage relationships. Current elicited in control bath solution (open circles), current during CAP application (open triangles), and difference current (solid circles). Each point represents the mean of four determinations from four DRG neurons. The holding potential was $-60 \mathrm{mV}$.

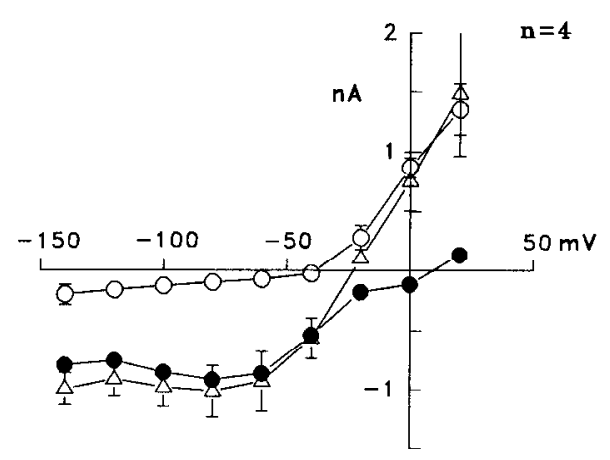

glia were then washed three times with $\mathrm{Mg}^{2+}$ - and $\mathrm{Ca}^{2+}$-free HBSS (Sigma). The ganglia were incubated in the warm HBSS $\left(37^{\circ} \mathrm{C}\right)$ containing $2.5 \mathrm{mg} / \mathrm{ml}$ trypsin (Boehringer Mannheim, Indianapolis, IN) and shaken gently for $30 \mathrm{~min}$. The trypsin-containing solution was centrifuged at $1000 \mathrm{rpm}$ for $10 \mathrm{~min}$. The pellet was washed gently two to three times with the culture medium to inhibit the enzyme activity. The pellet was resuspended in the culture medium, gently triturated with a fire-polished Pasteur pipette, filtered through Nytex-40 nylon mesh, and plated on round glass coverslips in small Petri dishes $\left(35 \times 12 \mathrm{~mm}^{2}\right)$. The glass coverslips were treated previously with poly-L-lysine $(0.5 \mathrm{mg} / \mathrm{ml})$ and dried. Cells were placed in a $37^{\circ} \mathrm{C}$ incubator and gassed with $95 \% \mathrm{O}_{2} / 5 \%$ $\mathrm{CO}_{2}$ atmosphere. Cells were used 2-4 $\mathrm{d}$ after plating.

Electrophysiology. Gigaseals were formed with borosilicate glass pipettes (Kimble, Toledo, $\mathrm{OH}$ ) coated with SYLGARD (Dow Corning, Midland, MI). Tip resistance of the pipettes was 2.5-5 M $\Omega$. To make a whole cell, a cell-attached patch was formed, and the cell membrane under the patch pipette was ruptured by gentle suction. After forming the whole cell, the capacitive transients were canceled at the beginning of each recording. For single-channel studies, cell-attached, outside-out, and inside-out patches were formed as described by Hamill et al. (1981). Single-channel and whole-cell currents were recorded with a patch-clamp amplifier (Axopatch 1D, Axon Instruments, Foster City, CA), filtered at $2.5 \mathrm{kHz}$ with an 8-pole, low-pass Bessel filter (Frequency Device, Haverhill, MA), digitized at $37 \mathrm{kHz}$ with a digital data recorder (Instrutech, Great Neck, NY), and stored on videotapes. The digitized data were imported to a personal computer (IBM PC/AT-486 compatible) to measure channel open probability $\left(P_{\mathrm{o}}\right)$, amplitude, and mean open time. $P_{\mathrm{o}}$ of single channels was obtained from the ratio of the area under the curve representing open events divided by the sum of the areas under the curves representing open and closed events. Channel activity was calculated as maximum number of channel in the patch $(N)$ times $P_{\mathrm{o}}$. Maximum number of channels was determined after full activation by CAP (in a condition in which channels in the patch were maximally activated). The amplitude histograms and open time histogram were analyzed for patches containing only one channel. The threshold amplitude for taking an opening event was set at 50\% (half-amplitude algorithm in FETCHAN, Axon Instruments), and the minimum duration was set at $100 \mu \mathrm{sec}$. Voltage-clamp pulse protocol was set by Clampex (Axon Instruments), and the voltage-clamped pulses were generated using a digital-to-analog converter (Warner Instruments, Hamden, CT).

Solutions. For whole-cell studies, the bath solution contained (in mM): $140 \mathrm{NaCl}, 5 \mathrm{KCl}, 1 \mathrm{CaCl}_{2}, 2 \mathrm{MgCl}_{2}, 10 \mathrm{HEPES}$, and 10 glucose, $\mathrm{pH} 7.4$. The pipette solution contained (in $\mathrm{mM}$ ): $140 \mathrm{KCl}, 5 \mathrm{EGTA}, 2 \mathrm{MgCl}_{2}$, and 10 HEPES, $\mathrm{pH}$ 7.2. In single-channel experiments, control bath and pipette solutions contained (in $\mathrm{mM}$ ): $140 \mathrm{NaCl}, 2 \mathrm{MgCl}_{2}, 5 \mathrm{EGTA}$, and 10 HEPES, pH 7.4, unless specified otherwise. CAP, CZP, and RTX were dissolved and stored as stock solutions in $100 \%$ ethanol $(10,10$, and $1 \mathrm{mM}$, respectively). The control and CAP solutions were delivered to the whole cell via a continuous flow system. All basic reagents were purchased from Sigma. ATP was obtained from Boehringer Mannheim. CAP, CZP, and RTX were purchased from Research Biochemical (Natick, MA). All values are expressed as mean $\pm \mathrm{SE}$.

\section{RESULTS}

\section{Whole-cell currents activated by CAP}

DRG neurons were used 2-4 d after culture. DRG neurons were easily detected because of their round soma and long processes. Because CAP affected primarily the small-diameter neurons (Wood et al., 1988), medium-to-small DRG neurons were selected and examined for the CAP effect. We first examined whether CAP could activate whole-cell currents in neonatal rat DRG neurons. Under the whole-cell configuration, the cell membrane potential of a DRG neuron was held at $-60 \mathrm{mV}$. Bath 
A

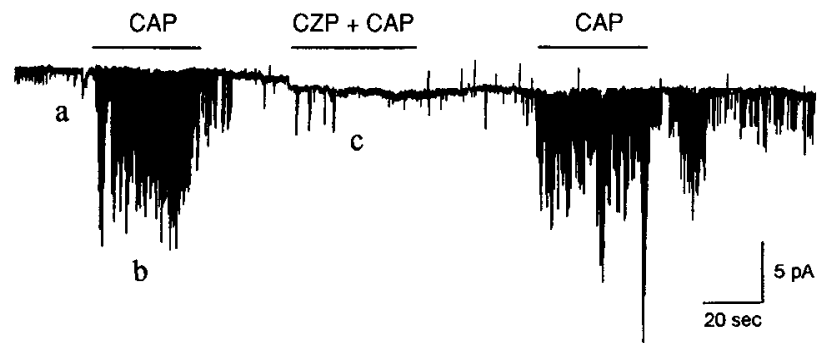

B

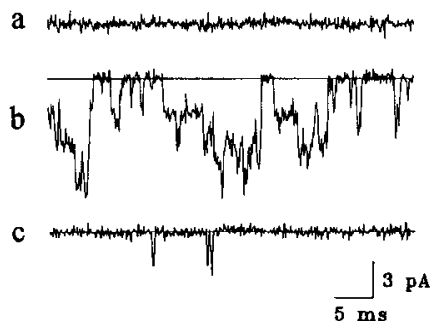

C

$\mathbf{D}$

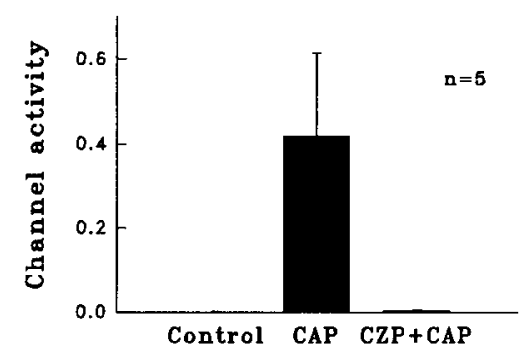

Figure 2. Activation of single-channel currents by CAP and block by CZP in an outside-out excised membrane patch. $A$, An outside-out membrane patch was held at $-60 \mathrm{mV}$. Both pipette and control bath solution contained (in mM): $140 \mathrm{Na}^{+}, 140 \mathrm{Cl}^{-}, 2 \mathrm{Mg}^{+}, 5$ EGTA, and $10 \mathrm{HEPES}$. $C A P(1 \mu \mathrm{M})$ - or $C Z P+C A P$ (10 and $1 \mu \mathrm{M}$, respectively)-containing solution was applied to the extracellular surface of patch membrane. $B$, Channel openings in an expanded time scale. Straight lines represent closed state of the channel. $C$, An amplitude histogram of channel openings recorded during CAP perfusion. $D$, A summary of CAP responses expressed in channel activity $\left(N^{*} P_{\mathrm{o}}\right)$ in five different isolated patches.

solution contained (in mM): $140 \mathrm{NaCl}, 5 \mathrm{KCl}, 1 \mathrm{CaCl}_{2}, 2 \mathrm{MgCl}_{2}$, 10 HEPES, and 10 glucose, $\mathrm{pH}$ 7.4. Pipette solution contained (in mM): $140 \mathrm{KCl}, 5$ EGTA, $2 \mathrm{MgCl}_{2}$, and 10 HEPES, pH 7.2. ATP (4 $\mathrm{mM}$ ) was added to the pipette solution to prevent opening of ATP-sensitive $\mathrm{K}^{+}$channels. After the holding current stabilized, the DRG neuron was perfused with $3 \mu \mathrm{M}$ CAP for $\sim 1$ min and then washed out. As shown in Figure $1 A$, CAP $(3 \mu \mathrm{M})$ activatcd an inward current that was reversible after washout. The inward current was blocked when $10 \mu \mathrm{M} \mathrm{CZP}$ was perfused together with CAP $(3 \mu \mathrm{M})$. The current activated by the second application to CAP was usually smaller than that produced by first application, presumably because of desensitization (Fig. 1A). Such inward currents were activated by CAP in 33 of 43 (77\%) DRG neurons.

Whole-cell current-voltage relationships were obtained during CAP application by applying square pulses of $400 \mathrm{msec}$ duration from -140 to $+20 \mathrm{mV}$ in $20 \mathrm{mV}$ increments. Figure $1 B$ shows the whole-cell currents before and during CAP application. Currents were averaged after two trials of the pulse paradigm. In the absence of CAP, very little sustained inward current, except a brief period at the beginning of each pulse, but a large sustained outward current was observed. CAP treatment increased the amount of inward current at all voltages below $-40 \mathrm{mV}$. CAPinduced current was obtained by subtraction (Fig. 1C, filled circles). As shown in Figure $1 C$, the CAP-sensitive current did not change markedly between -140 and $-60 \mathrm{mV}$. After further depolarization, however, the current became smaller and reversed close to $0 \mathrm{mV}(n=4)$. Thus, the difference current showed an outward rectification. These results showed that CAP-sensitive ion currents were present in neonatal rat DRG neurons.

\section{Activation of single-channel current by CAP}

The presence of single-channel currents activated by CAP was first examined using isolated membrane patches in outside-out configuration. We initially used $\mathrm{Na}^{+}$as the charge carrier. Thus, pipette and bath solution contained (in $\mathrm{mM}$ ): $140 \mathrm{NaCl}, 2 \mathrm{MgCl}_{2}$, 10 HEPES, and 5 EGTA. Membrane potential was held at -60 $\mathrm{mV}$. No channel openings were present in outside-out patches under these experimental conditions. After perfusion of the extracellular membrane with $1 \mu \mathrm{M}$ CAP, however, ion channels became active and remained open in the presence of CAP (Fig. $2 A$ ). Perfusion with control solution caused the channels to close within $\sim 30 \mathrm{sec}$. The same channels did not open when the patch was perfused with $10 \mu \mathrm{M}$ CZP and $1 \mu \mathrm{M}$ CAP together. After washout of both agents, reapplication of CAP caused a similar activation of the single-channel currents in the same patch. Identical results were obtained in four other outside-out patches. Current tracings at an expanded time scale show multiple channel openings in the presence of CAP (Fig. $2 B$ ). In these patches, channel current amplitudes were multiples of the single-channel amplitude, showing that one type of channel was activated (Fig. $2 B, C)$. These results are summarized in Figure $2 D$, which also shows complete inhibition of the CAP-induced current by CZP.

Because RTX has CAP-like actions on sensory neurons (Szallasi and Blumberg, 1989; Dray et al., 1990), we tested whether RTX could also activate the same channel activated hy CAP. Extracellular application of CAP $(0.5 \mu \mathrm{M})$ to an outside-out patch caused the reversible opening of channels. In the same patch, application of $2 \mathrm{nM}$ RTX caused greater activation of channels with identical single-channel conductance (Fig. $3 A)(42.3 \pm 1.3$ vs $42.6 \pm 1.1 \mathrm{pS} ; n=4)$. RTX, therefore, was much more potent than CAP in activating the channel, in keeping with the greater potency of the toxin on its effects on sensory neurons (Dray et al., 1990; Winter et al., 1990). Similar results were observed in three additional patches, showing that RTX at nanomolar concentrations (2-10 nM) was able to activate the same channel opened by CAP.

The activation of ion channels was also observed in cellattached patches with CAP added to the pipette. As shown in Figure $3 B$, openings of sevcral channels were usually present when the cell membrane potential was held at $-60 \mathrm{mV}$ in symmetrical $140 \mathrm{mM} \mathrm{Na}^{+}$. These channels were not present in cellattached patches without CAP or RTX in the pipette in any of the 60 patches tested. After formation of an inside-out patch, the channels remained open for the duration of the experiment $(\sim 20$ $\mathrm{min}$ ), although the activity changed slightly. Because solution in the bath did not contain any of cytosolic signal transduction mediators such as ATP, GTP, $\mathrm{Ca}^{2+}$, or phospholipids, it was unlikely that opening of the channels was mediated by the cytosolic factors. These results show that activation of single channels 
A

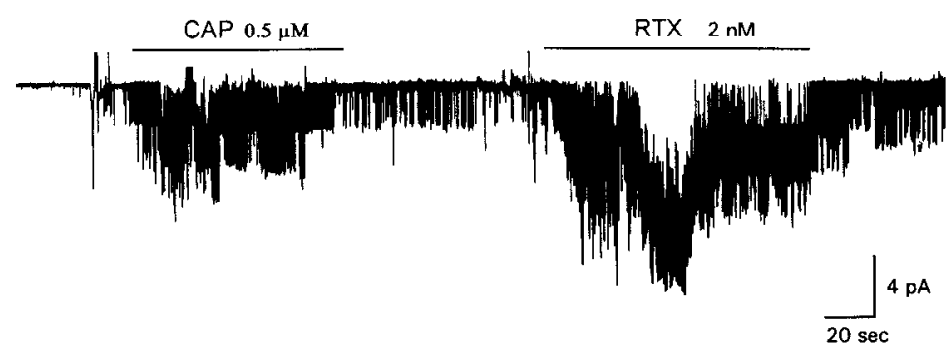

B

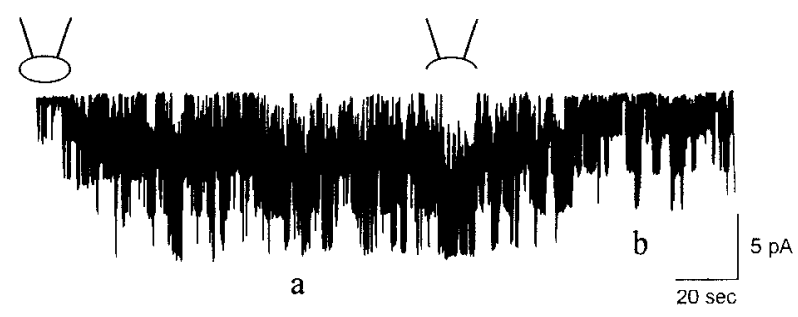

Figure 3. $A$, Activation of a $C A P$-activated channel by $R T X$ $(2 \mathrm{nM})$ in an outside-out membrane patch held at $-60 \mathrm{mV} . B$, Single-channel openings in a cell-attached and inside-out patch. Pipette contained $0.5 \mu \mathrm{M}$ CAP. Bath contained symmetrical $140 \mathrm{~mm} \mathrm{NaCl}$ solution. The patch was held at $-60 \mathrm{mV}$.

by CAP does not require intracellular second messengers, and is likely to be via a direct, membrane-delimited pathway.

To determine whether the effect of CAP was dose-dependent, the extracellular side of an outside-out patch was perfused with CAP starting at $0.03 \mu \mathrm{M}$, and the concentration progressively increased to $10 \mu \mathrm{M}$, allowing a relatively steady-state level of channel activity to be achieved at each concentration of CAP. As shown in Figure 4, CAP activated the channel starting at $0.3 \mu \mathrm{M}$, and maximal activation was present at $10 \mu \mathrm{M}$. The relative channel activity $\left(N^{*} P_{\mathrm{o}}\right)$ was plotted as a function of CAP concentration in the bath (Fig. $4 B$ ). The channel activity observed at $10 \mu \mathrm{M}$ CAP was taken as 1.0 for each patch. 'I'he normalized data points obtained from five patches were fitted by linear regression to the Hill equation:

$$
N^{*} P_{\mathrm{o}}=\frac{1}{1+\left(K_{\mathrm{D}} /[\mathrm{CAP}]\right)^{n}},
$$

where $K_{\mathrm{D}}$ is the half-maximal concentration of CAP in activating the channel, [CAP] is the concentration of CAP, and $n$ is the Hill coefficient. The $K_{\mathrm{D}}$ value obtained from the regression was 1.1 $\mu \mathrm{M}$, and the Hill coefficient was 1.8. The Hill coefficient of $\sim 2$ suggests that two sites for CAP may be present in the receptor or channel and that binding occurs in a positive, cooperative manner.

\section{Single-channel properties}

Channel openings at different membrane potentials in symmetrical $140 \mathrm{~mm} \mathrm{Na}^{+}$are shown in Figure $5 A$. Amplitude histograms were obtained from openings at each membrane potential, and the mean amplitude values were plotted as a function of membrane potential to obtain the current-voltage relationship (Fig. $5 B$ ). The single-channel slope conductances were $45.3 \pm 1.0 \mathrm{pS}$ at $-60 \mathrm{mV}$ and $80.0 \pm 4.2 \mathrm{pS}$ at $+60 \mathrm{mV}(n=9)$, showing that the current was outwardly rectifying (Fig. $5 B$ ).

$P_{\text {o }}$ was significantly greater at depolarized than at hyperpolarized potentials in all patches studied. In inside-out patches with 1 $\mu \mathrm{M}$ CAP in the pipette, $P_{\mathrm{o}}$ values of the channels were $0.04 \pm 0.01$ and $0.1 \pm 0.03$ at -80 and $-60 \mathrm{mV}$, respectively, but the $P_{\mathrm{o}}$ values increased greatly to $0.63 \pm 0.14$ and $0.64 \pm 0.13$ when membrane potentials were held at +60 and $+80 \mathrm{mV}$, respectively $(n=5)$. The relative $P_{o}$ as a function of membrane potential is shown in Figure 6 . The mean values from five different patches were plotted as a function of voltage and fitted by linear regression to the Boltzmann distribution given by:

$$
P_{\mathrm{o}}=\frac{1}{1+e^{-\left(V-V_{1 / 2}\right) K}}
$$

where $V_{1 / 2}(-8.8 \mathrm{mV})$ is the half-maximal voltage and $K$ is the slope. An $e$-fold change in $P_{\mathrm{o}}$ ratio occurred every $28.8 \mathrm{mV}$ for the CAP-activated channel.

Ion selectivity of the channel was determined by ionsubstitution experiments in inside-out patches. In these experiments, pipette solution (extracellular side) contained $140 \mathrm{~mm}$ $\mathrm{NaCl}$ and $1 \mu \mathrm{M} \mathrm{CAP}$. To study whether the channel was permeable to $\mathrm{Na}^{+}$or $\mathrm{Cl}^{-}$, shifts in the reversal potential were examined at different concentrations of $\mathrm{NaCl}$ in the bath (intracellular side). 
$\mathbf{A}$

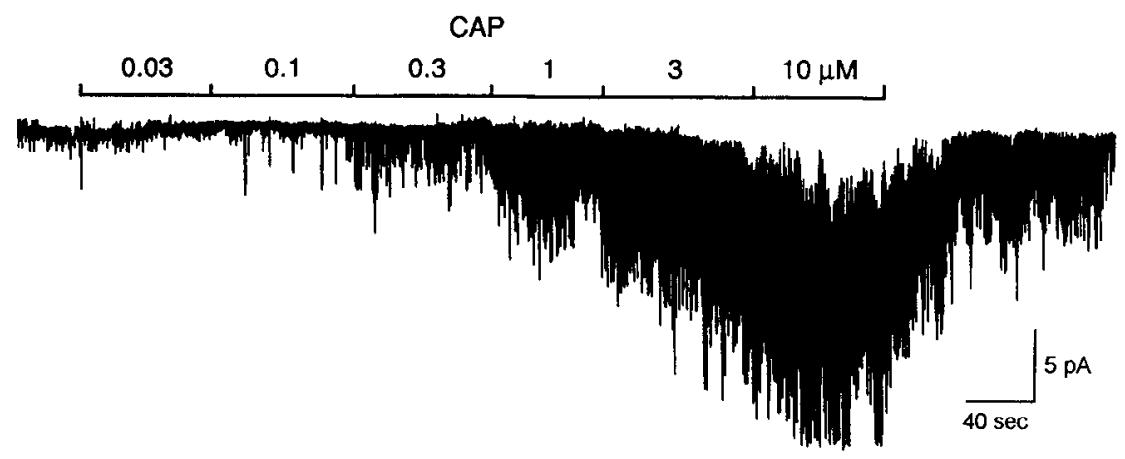

\section{B}

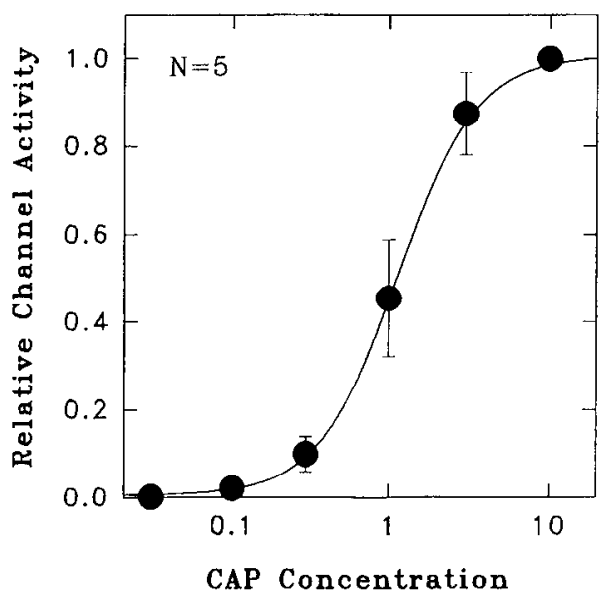

Changing the bath $\mathrm{NaCl}$ concentration from 140 to $57 \mathrm{~mm}$ shifted the reversal potential from 0 to $+25.2 \pm 1.1 \mathrm{mV}(n=6)$, which is close to the expected Nernst potential for a $\mathrm{Na}^{+}$-selective channel $(22.6 \mathrm{mV}$ ) (Fig. $7 A, B)$. Similar experiments were conducted in bath solution containing $300,92,57$, and $36 \mathrm{~mm} \mathrm{NaCl}$, and reversal potentials were plotted as a function of bath $\mathrm{NaCl}$ concentration in a semilogarithmic scale. The slope of the fitted line was $-58.4 \mathrm{mV} /$ decade, suggesting that the channel was selective for $\mathrm{Na}^{+}$(Fig. $7 B$ ). We further tested ion selectivity by using nonpermeable cation and anion. When $\mathrm{NaCl}$ in the bath was replaced with $\mathrm{Na}^{+}$-glutamate, inward and outward currents similar to those present with $140 \mathrm{~mm} \mathrm{NaCl}$ were observed $(n=5)$. When $N$-methyl-D-glucamine replaced $\mathrm{Na}^{+}$in the bath in insideout patches, no detectable outward current was present $(n=5)$. Therefore, the channel was clearly permeable to $\mathrm{Na}^{+}$but not to $\mathrm{Cl}^{-}$.

Replacing bath $\mathrm{NaCl}$ with an equimolar amount of $\mathrm{KCl}(n=3)$, $\mathrm{CsCl}(n=3), \mathrm{RbCl}(n=2)$, or LiCl $(n=3)$ did not significantly shift the reversal potentials $(-4.3 \pm 1.1 \mathrm{mV} ; n=4)$, indicating that the channel discriminated poorly among monovalent cations. Small differences, however, in single-channel conductances were noted with different cations (Fig. 8A). For example, with $\mathrm{Li}^{+}$and $\mathrm{Rb}^{+}$as charge carriers, the conductances were $43.3 \pm 3.9$ and 69.9 $\pm 6.1 \mathrm{pS}$ at $+60 \mathrm{mV}$, respectively. To determine the permeability of the CAP-activated channcl to $\mathrm{Ca}^{2+}$, pipctte $\mathrm{NaCl}$ in insidc-out patches was replaced with $100 \mathrm{mM} \mathrm{CaCl}_{2}$. As shown in Figure $8 B$,
Figure 4. Dose-dependent activation of the CAPactivated channel. $A, C A P$ at different concentrations ranging from 0.03 to $10 \mu \mathrm{M}$ was perfused to the outer surface of an outside-out membrane patch in symmetrical $140 \mathrm{~mm} \mathrm{NaCl}$ solution. The tracing shown was the one in which channel activity at $3 \mu \mathrm{M}$ CAP was $59 \%$ of that at $10 \mu \mathrm{M}$. B, A summary of dose-response relationship expressed in relative channel activity $\left(N^{*} P_{\circ}\right)$ versus CAP concentration. Data points $(n=5)$ were fittcd to Hill's cquation. $K_{\mathrm{D}}=1.1 \mu \mathrm{M}$. Bars represent $\mathrm{SE}$.
CAP also activated inward single-channel currents, indicating that the channel was permeable to $\mathrm{Ca}^{2+}$. The conductance of inward currents carried by $\mathrm{Ca}^{2+}$ at $-60 \mathrm{mV}$ was $24.2 \pm 0.01 \mathrm{pS}(n=7)$. To get an accurate reversal potential, the current-voltage relationship in the single-channel currents in this preparation was fitted by an exponential equation: $I=e^{\left(a^{*} V+b\right)}+c$. The reversal potential with $100 \mathrm{mM} \mathrm{CaCl}_{2}$ thus calculated was $-4.1 \mathrm{mV}$, and the permeability ratio, $P_{\mathrm{Ca}} / P_{\mathrm{Na}}$, calculated from the modified constant-field equation was 0.24 (Fatt and Ginsborg, 1958).

\section{Effect of acid on the channel}

An acidic medium $(\mathrm{pH}<6.2)$ has been reported to activate a CAP-sensitive current and, therefore, extracellular $\mathrm{H}^{+}$ion has been considered to be one of the endogenous activators of the CAP channel (Bevan and Geppetti, 1994; Liu and Simon, 1994). Therefore, we tested whether acid could activate the CAPactivated channel in DRG neurons used in this study. An acidic solution identical in composition to that of control bath solution, except $\mathrm{pH}$ ( $\mathrm{pH} 5.8-6.0$ ), was applied to the extracellular surface of DRG neurons in whole-cell or outside-out patches. In all six cells, CAP $(0.5-1 \mu \mathrm{M})$ activated large, slowly desensitizing currents. Acidic solution ( $\mathrm{pH} 5.8-6.0$ ), however, failed to activate the same type of whole-cell currents (Fig. 9A). Activation of the inward currents by CAP was observed after washout of the acidic solution. In two cells, we observed activation of a small and rapidly inactivating whole-cell current by acidic solution $(\mathrm{pH}$ 
A

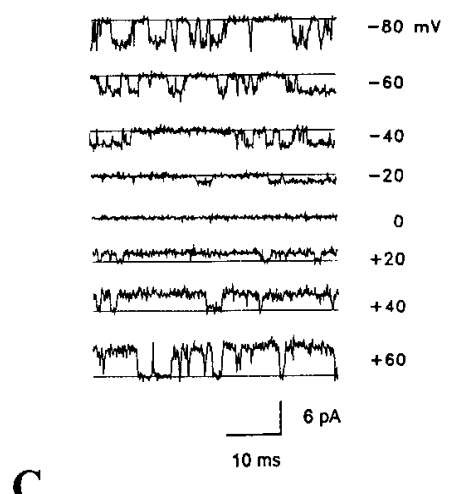

C

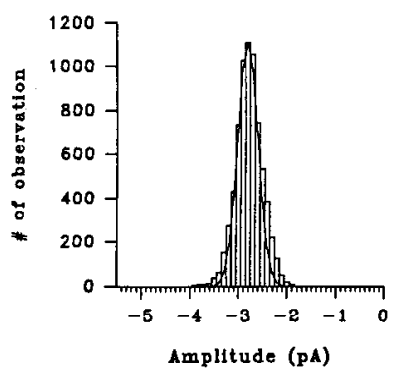

B
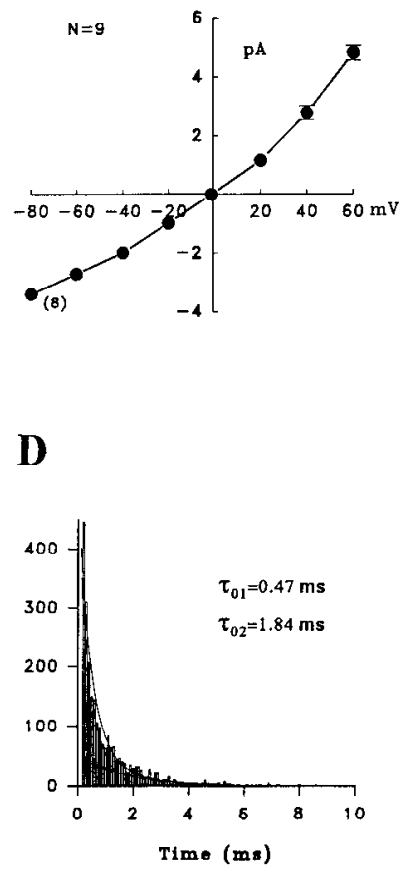

Figure 5. Kinetic properties of CAP-activated channel. $A$, Tracings of single-channel currents held at different membrane potentials ranging from -80 to $+60 \mathrm{mV}$ in an outside-out patch. The channcl was activated by $10 \mu \mathrm{M} \mathrm{CAP}$ in the bath solution under the symmetrical $140 \mathrm{~mm} \mathrm{NaCl}$ condition. $B$, Current-voltage relationship of single-channel currents. Each data point was averaged from nine patches of either inside-out or outside-out configuration. Bars represent SE. The error bars are small, and some are inside circles. $C$, An amplitude histogram of channel openings (7009 openings) recorded from the patch held at $-60 \mathrm{mV}$ as illustrated in $A . D$, Open time histogram of the channel obtained from the same patch. Time bins were $0.1 \mathrm{msec}$. The histogram of 2499 openings was fitted to a biexponential function with time constants $0.47(65 \%)$ and 1.84 $(35 \%)$ msec.

$5.8-6.0$ ), similar to that reported previously (Bevan and Yeats, 1991; Liu and Simone, 1994). Failure of acidic medium to activate the CAP-sensitive current was also confirmed in excised patches. In outside-out patches, acidic bath solution $(\mathrm{pH} 6.0)$ failed to activate the CAP-activated channels in all patches studied $(n=8$; Fig. $9 B$ ). In the same patches, however, application of $0.5-1 \mu \mathrm{M}$ CAP produced a clear activation of single channels. The results from four outside-out patches are shown in Figure $9 \mathrm{C}$. These results show that acid is not an endogenous activator of the CAP-activated channel that we observe in this study.

\section{DISCUSSION}

CAP causes intense burning pain because of its excitatory action on sensory neurons (Geppetti et al., 1988; Simone et al., 1989). The excitation of sensory fibers is attributable to an increase in ion conductance and suhsequent depolarization (Marsh et al., 1987). Although whole-cell currents activated by CAP have been described recently (Bevan et al., 1992; Liu and Simon, 1994), single channels that give rise to the whole-cell current have not been clearly identified or characterized. In this study, we found a nonselective cation channel that was activated by CAP in a concentration-dependent manner. RTX, a more potent structural

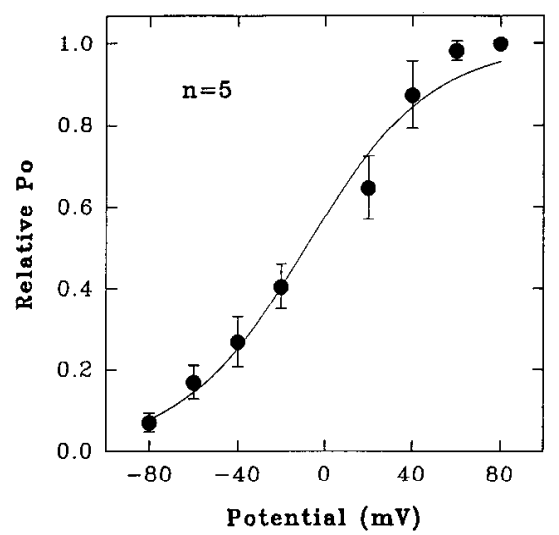

Figure 6. Voltage dependence of the CAP-activated channel. Channel openings at different membrane potentials were recorded from five separate inside-out patches containing $1 \mu \mathrm{M} \mathrm{CAP}$ in the pipette, and $P_{\mathrm{o}}$ at each potential was determined. The relative mean $P_{\mathrm{o}}$ was plotted as a function of membrane potential and fitted to the Boltzmann equation as described in the text.

analog of CAP, also activated the same channel at much lower concentrations. Activation of the channel by CAP was antagonized by CZP, a putative CAP-receptor blocker (Dickenson and Dray, 1991; Bevan et al., 1992). The CAP-activated channel was permeable to cations, including $\mathrm{Ca}^{2+}$. These findings indicate that the CAP-induced depolarization of the sensory neuron is attributable to opening of this nonselective cation channel present in DRG neurons.

The results that the channel was activated by application of CAP directly to the extracellular side of inside-out patches suggest that it may belong to the family of ligand-gated ion channels. No intracellular second messengers such as GTP, ATP, or $\mathrm{Ca}^{2+}$ were found to be necessary for activation by CAP. RTX as a phorbol ester analog is known as a weak activator of protcin kinase C (Ellis ct al., 1987). Protcin kinase $\mathrm{C}$, however, is unlikely to be involved in channel activation by CAP or RTX, because the toxins activated the channels in excised patches in the absence of any necessary cofactors such as $\mathrm{Ca}^{2+}$ or phospholipids. Recently, a protein in DRG neurons that specifically bound to RTX was cloned and sequenced (Ninkina et al., 1994). Unlike other ligand-gated ion channels such as nicotinic acid, GABA , glycine, or glutamate receptor, which have four transmembrane domains in their subunit proteins (Betz, 1990), the RTX-binding protein was described as having only a single transmembrane domain and as lacking sequence homology with other channel proteins. Furthermore, when expressed in oocytes, the protein showed no channel-like activity (Ninkina et al., 1994). Therefore, the RTX-binding protein could be a transducer that is coupled to the ion channel. Thus, CAP receptor itself may not be the channel protein; it could be an associated regulatory protein that gates the channel directly.

The activation of an ionic current by an exogenous substance like CAP has raised a question of whether there is an endogenous activator of such a current. Because acid and CAP have similar actions in causing pain, it has been suggested that acid may be an endogenous activator (for review, see Bevan and Geppetti, 1994). Acidic condition occurs with conconitant painful sensation when tissues become ischemic or inflammatory (Peer, 1955; Jacobus et 


\section{A}

$140 \mathrm{mM} \mathrm{Na}^{+}$
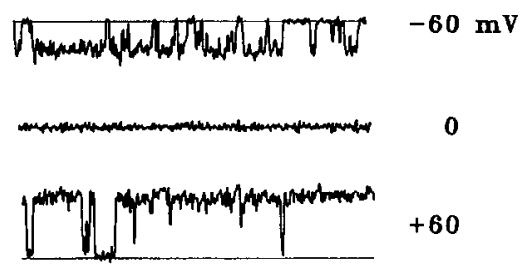

0

$+60$

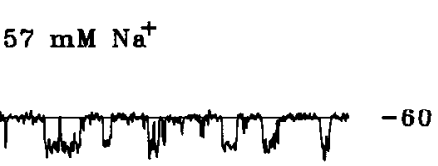

(1)

0

$+60$
B

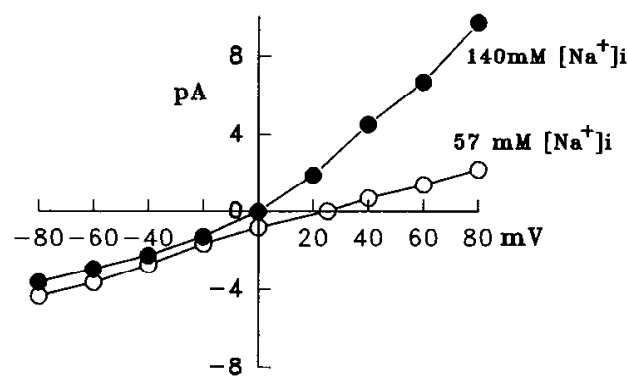

Figure 7. Ion selectivity of the CAPactivated channels. $A$, Current recordings from an inside-out patch at different potentials. The patch contained $140 \mathrm{~mm} \mathrm{NaCl}$ or 1 $\mu \mathrm{M}$ CAP in the pipette and was exposed to 140 or $57 \mathrm{mM} \mathrm{Na}^{+}$in the bath. B, Currentvoltage relationships under the two $\mathrm{Na}^{+}$ concentration gradient conditions. As the bath $\mathrm{Na}^{+}$concentration was changed from $140(0)$ to $57(\mathrm{O}) \mathrm{mm}$, the reversal potential shifted from 0 to $+25.2 \pm 1.1 \mathrm{mV}$, indicating that the channel is permeable to $\mathrm{Na}^{+}$but not $\mathrm{Cl}^{-}$. Bottom right, Reversal potentials in a different $\mathrm{NaCl}$ gradient between pipette and bath solution. The data points were fitted to a regression line. The slope of the line was $-58.4 \mathrm{mV} /$ decade. Numbers in $p a$ rentheses represent number of patches recorded. al., 1977). Direct application of acid to the receptive field excites sensory nerve fibers, and the excitation is comparable with that evoked by CAP (Steen et al., 1992). Both CAP and acid were found to produce similar whole-cell currents in trigeminal neurons (Liu and Simon, 1994). Moreover, release of peptides such as CGRP from bronchial smooth muscle by acid was blocked by CZP (Santicioli et al., 1993). The CGRP release evoked by acid is not found when CAP-sensitive neurons are lost after pretreatment with CAP (Geppetti et al., 1991). Thus, these findings suggest that acid may be an endogenous CAP. However, there are other studies that do not support the view that acid and CAP have similar mechanism of action. For example, ${ }^{86} \mathrm{Rb}^{+}$efflux from DRG cultures induced by acid was not blocked by CZP (Bevan et al., 1992). Also, there was no cross-correlation between acid and CAP in activating primary afferents in a rat saphenous nerve, although both were capable of activating the nerve fibers (Steen et al., 1992). In our study using outside-out patches, acid failed to activate the CAP-activated channel, indicating that $\mathrm{H}^{+}$did not work via the same pathway as that used by CAP in activating the sensory neurons. Our results also suggest that the putative CAP receptor protein, whether it is the channel itself or an associated regulatory protein, is not sensitive to acidic $\mathrm{pH}$.

In summary, we report the presence of a nonselective cation channel that is activated by CAP in neonatal rat DRG neurons. The channel was activated by $C \wedge P$ and blocked by CZP in excised membrane patches in the absence of any intracellular second messenger, suggesting that the channel could be a ligand-gated ion channel. The channel was also activated by RTX in the nanomolar range, but not by acidic solution. When activated by CAP, the channel may increase cation conductance, allowing influx of cations which, in turn, leads to depolarization of the sensory neurons. The channel that we identified is likely to pro-
A
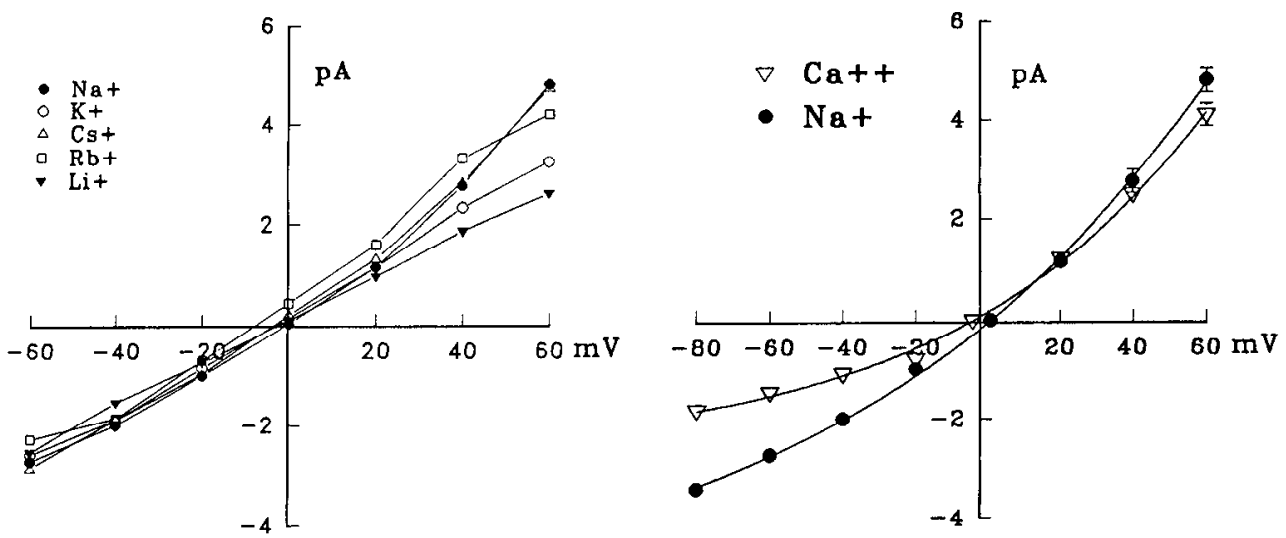

Figure 8. Cation selectivity of the CAP. activated channel. $A$, Inside-out patches were formed with pipettes containing $140 \mathrm{~mm} \mathrm{NaCl}$. Current-voltage relationships were obtained after bath solutions were changed from $140 \mathrm{~mm} \mathrm{NaCl}$ to 140 $\mathrm{mM} \mathrm{KCl}, \mathrm{CsCl}, \mathrm{RbCl}$, or $\mathrm{LiCl}$. The current-voltage curve for $\mathrm{Na}^{+}$is the same as illustrated in Figure 5. B, The channel was permcable to $\mathrm{Ca}^{2+}$. In this expcriment, pipette solutions were filled with $100 \mathrm{mM} \mathrm{CaCl}_{2}$ and $1 \mu \mathrm{M}$ CAP. Currentvoltage relationships were obtained after inside-out patches were formed $(n=7)$. The bath solution contained $140 \mathrm{~mm}$ $\mathrm{NaCl}$. To obtain reversal potentials, currents at each potential were fitted by an exponential equation described in the text. $P_{\mathrm{Ca}} / P_{\mathrm{Na}}=0.24$. 
$\mathbf{A}$

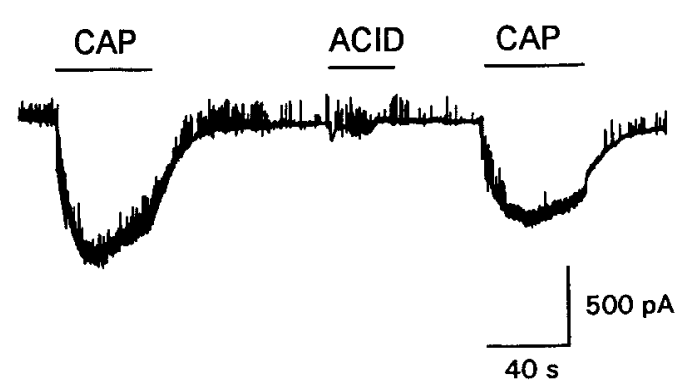

B

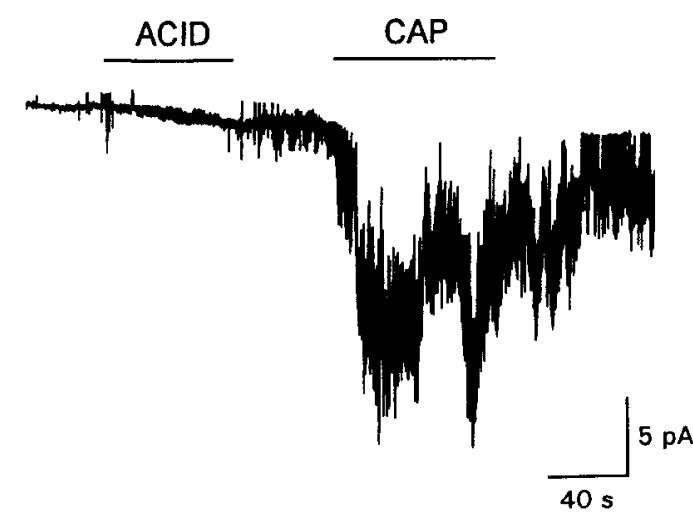

C

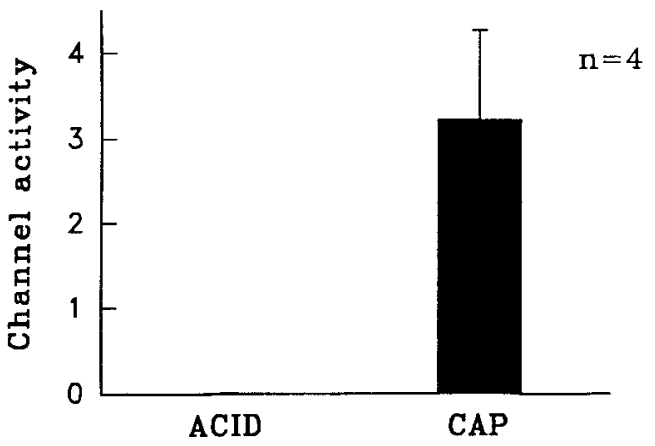

Figure 9. Effect of acidic solution on the CAP-activated channel. $A, C A P$ $(0.5 \mu \mathrm{M})$ applied to a DRG cell evoked an inward whole-cell current. Acidic bath solution ( $A C I D ; \mathrm{pH} 5.8)$, however, failed to evoke the inward current. Small deffections were artifacts caused by small air bubbles generated in the perfusion system. $B$, Acidic bath solution $(A C I D ; \mathrm{pH} 6.0$, symmetrical $140 \mathrm{~mm} \mathrm{NaCl}$ ) was perfused to the extracellular surface of an outside-out patch held at $-60 \mathrm{mV}$. Single-channel openings were not observed during acid application. Unitary channel openings, however, were seen when $0.5 \mu \mathrm{M} C A P$ (pH 7.4) was applied. $C$, Summary of effects of $C A P$ and $A C I D(\mathrm{pH} 6.0)$ on the CAP-activated channel $(n=4)$.

duce the macroscopic cation current that underlies sensory transduction in pain transmission.

\section{REFERENCES}

Betz H (1990) Ligand-gated ion channels in the brain: the amino acid and receptor superfamily. Neuron 5:383-392.

Bevan S, Geppetti P (1994) Protons: small stimulants of capsaicinsensitive sensory nerves. Trends Neurosci 17:509-512.
Bevan S, Yeats J (1991) Protons activate a cation conductance in a subpopulation of rat dorsal root ganglion neurons. J Physiol (Lond) 433:145-161.

Revan S, Hothi S, Hughes G, Tames IF, Rang HP, Shah K, Walpole CS.I, Yeats JC (1992) Capsazepine: a competitive antagonist of the sensory neurone excitant capsaicin. Br J Pharmacol 107:544-552.

Dickenson AH, Dray A (1991) Selective antagonism of capsaicin by capsazepine: evidence for a spinal receptor site in capsaicin-induced antinociception. Br J Pharmacol 104:1045-1049.

Dray A, Bettaney J, Forster P (1989) Capsaicin desensitization of peripheral nociceptive fibers does not impair sensitivity to other noxious stimuli. Neurosci Lett 99:50-54.

Dray A, Bettaney J, Forster P (1990) Resiniferatoxin: a potent capsaicinlike stimulator of peripheral nociceptors in the neonatal rat tail in vitro. Br J Pharmacol 99:323-326.

Ellis CA, Brooks SF, Brooks G, Evans AT, Morrice N, Evans FT, Aitken A (1987) The effects of phorbol esters with different biological activities on protein kinase C. Phytother Res 1:187-190.

Fatt P, Ginsborg BL (1958) The ionic requirements for the production of action potentials in crustacean muscle fibers. J Physiol (Lond) 142:516-543.

Geppetti P, Fusco B, Marabini S, Maggi CA, Fanciullacci M, Sicuteri F (1988) Secretion, pain and sneezing induced by the application of capsaicin to the nasal mucosa in man. Br J Pharmacol 93:509-514.

Geppetti P, Del Bianco E, Patacchini R, Santicioli P, Maggi CA, Tramontana M (1991) Low pH-induced release of calcitonin gene-related peptide from capsaicin-sensitive sensory nerves: mechanism of action and biological response. Neuroscience 41:295-301.

Hamill OP, Marty A, Neher E, Sakmann B, Sigworth FJ (1981) Improved patch-clamp techniques for high-resolution current recording from cells and cell-free membrane patches. Pflügers Arch 391:85-100.

IIayes AG, Skingle M, Tyres MB (1981) Effect of single doses of capsaicin on nociceptive thresholds in the rodent. Neuropharmacology 20:505-511.

Holzer P (1991) Capsaicin: cellular targets, mechanisms of action, and selectivity for thin sensory neurons. Pharmacol Rev 43:143-201.

Jacobus WE, Taylor GJ, Hollis DP, Nunnally RL (1977) Phosphorus nuclear magnetic resonance of perfused working rat heart. Nature 265:756-758

Jancsó G, Kiraly E, Jancsó-Gabor A (1977) Pharmacologically induced selective degeneration of chemosensitive primary sensory neurones. Nature 270:741-743.

LaMotte RH, Simone DA, Baumann TK, Shain CN, Alreja M (1988) Hypothesis for novel classes chemoreceptors mediating chemogenic pain and itch. In: Pain research and clinical management (Dubner R, Gebhart GF, Bond MR, eds), pp 529-535. Amsterdam: Elsevier.

Lang E, Novak A, Reeh PW, Handwerker HO (1990) Chemosensitivity of fine afferents from rat skin in vitro. J Neurophysiol 63:887-901.

Liu L, Simon SA (1994) A rapid capsaicin-activated current in rat trigeminal ganglion neurons. Proc Natl Acad Sci USA 91:738-741.

Maggi CA, Patacchini R, Santicioli P, Guiliani S, Geppetti P, Meli A (1988) Protective action of ruthenium red toward capsaicin desensitization of sensory fibers. Neurosci Lett 88:201-205.

Maggi CA, Lippe IT, Giuliani S, Abelli L, Somma V, Geppetti P, Jancsó G, Santicioli P, Meli A (1989) Topical versus systemic capsaicin desensitization: specific and unspecific effects as indicated by modification of reflex micturition in rats. Neuroscience 31:745-756.

Marsh SJ, Stansfeld CE, Brown DA, Davey R, McCarthy D (1987) The mechanism of action of capsaicin on sensory c-type neurons and their axons in vitro. Neuroscience 23:275-289.

Nagy JI, Hunt SP (1983) The termination of primary afferents within the dorsal horn: evidence for rearrangement following capsaicin treatment. J Comp Neurol 218:145-158.

Nagy JI, Iversen LL, Goedert M, Chapman D, Hunt SP (1983) Dosedependent effects of capsaicin on primary sensory neurons in the nennatal rat. J Neurosci 3:399-406.

Ninkina NN, Willoughby JJ, Beech MM, Coote PR, Wood JN (1994) Molccular cloning of a resiniferatoxin-binding protein. Mol Brain Res 22:39-48.

Peer LA (1955) Transplantation of tissues. Baltimore: Williams \& Wilkins.

Santicioli P, Del Bianco E, Figini M, Bevan S, Maggi CA (1993) Effect of capsazepine on the release of calcitonin gene-related peptide-like immunoreactivity (CGRP-LI) induced by low $\mathrm{pH}$, capsaicin and potassium in rat soleus muscle. Br J Pharmacol 110:609-612. 
Simone DA, Ngeow JYF, Putterman GJ, LaMotte RH (1987) Hyperalgesia to heat after intradermal injection of capsaicin. Brain Res 418:201-203.

Simone DA, Baumann TK, LaMotte RH (1989) Dose-dependent pain and mechanical hyperalgesia in humans after intradermal injection of capsaicin. Pain 38:99-107.

Simone DA, Sorkin LS, Oh U, Chung JM, Owens C, LaMotte RH, Willis WD (1991) Neurogenic hyperalgesia: central neural correlates in responses of spinothalamic tract neurons. J Neurophysiol $66: 228-246$.

Steen KH, Reeh PW, Anton F, Handwerker HO (1992) Protons selectively induce lasting excitation and sensitization to mechanical stimulation of nociceptors in rat skin in vitro. $\mathrm{J}$ Neurosci 12:86-95.

Szallasi A, Blumberg PM (1989) Resiniferatoxin: a phorbol-related diterpene, acts as an ultrapotent analog of capsaicin, the irritant constituent in red peppers. Neuroscience 30:515-520.

Szallasi A, Blumberg PM (1990) Specific binding of resiniferatoxin, an ultrapotent capsaicin analog, by dorsal root ganglion membranes. Brain Res 524:106-111.

Szallasi A, Blumberg PM (1991) Characterization of vanilloid receptors in the dorsal horn of pig spinal cord. Brain Res 547:335-338.

Szallasi A, Blumberg PM (1993) Mechanisms and therapeutic potential of vanilloids (capsaicin-like molecules). Adv Pharmacol 24:123-155.
Szolcsanyi J (1987) Selective responsiveness of polymodal nociceptors of rabbit ear to capsaicin, bradykinin and ultra-violet irradiation. J Physiol (Lond) 388:9-23.

Szolcsanyi J, Jancsó-Gabor A (1975) Sensory effects of capsaicin congeners. I. Relationship between chemical structure and pain producing potency of pungent agents. Drug Res 25:1877-1881.

Szolcsanyi J, Jancsó-Gabor A (1976) Sensory effects of capsaicin congeners. II. Importance of chemical structure and pungency in desensitizing activity of capsaicin-type compounds. Drug Res 26:33-37.

Walpole CSJ Wrigglesworth R, Bevan S, Campbell EA, Dray A, James IF, Perkins MN, Reid DJ, Winter J (1993) Analogues of capsaicin with agonist activity as novel analgesic agents: structure-activity studies. I. The aromatic " $\Lambda$-region." J Med Chem 36:2362-2372.

Winter J, Dray A, Wood JN, Yeats JC, Bevan S (1990) Cellular mechanism of action of resiniferatoxin: a potent sensory neuron excitotoxin. Brain Res 520:131-140.

Winter J, Walpole CSJ, Bevan S, James IF (1993) Characterization of resiniferatoxin binding sites on sensory neurons: co-regulation of resiniferatoxin binding and capsaicin sensitivity in adult rat dorsal root ganglia. Neuroscience 57:747-757.

Wood JN, Winter J, James IF, Rang HP, Yeats J, Bevan S (1988) Capsaicin-induced ion fluxes in dorsal root ganglion cells in culture. J Neurosci 8:3208-3220. 